\title{
CONF.970834--15
}

\section{THE ROLE OF GALLIUM SULFIDE IN SrS:Ce GRAIN GROWTH}

\author{
N. D. Evans, A. Naman*, P. M. Rice**, K. S. Jones*, and P. H. Holloway*
}

Oak Ridge Institute for Science and Education, P.O. Box 117, Oak Ridge, TN 37831

"Dept. of Materials Science and Engineering, University of Florida, P.O. Box 116400, Gainesville, FL 32611

**Metals and Ceramics Division, Oak Ridge National Laboratory, P.O. Box 2008, Oak Ridge, TN 37831

Whereas efficient red (ZnS:Mn) and green (ZnS:Tb) phosphors are available for full-color flat-panel display technology, efficient blue phosphors are still under development. SrS:Ce is being investigated as a suitable material. As part of a larger study, annealed SrS:Ce films produced from sputter targets incorporating $\mathrm{Ga}_{2} \mathrm{~S}_{3}$ were found to be five times brighter than films produced from targets containing no $\mathrm{Ga}_{2} \mathrm{~S}_{3}$. Consequently, the significance of added gallium sulfide to the morphology of SrS:Ce films during annealing is being investigated.

Following deposition, plan view specimens of films were prepared for transmission electron microscopy by mechanical grinding, dimpling, and $\mathrm{Ar}^{+}$milling. Films were examined in a Philips $\mathrm{CM} 12$, and a JEOL $200 \mathrm{CX}$. Additionally, EDS line scans were obtained in the scanning-transmission mode of a Philips CM200FEG, integrated with an EMiSPEC Vision acquisition system. The EDS line scans were defined as a series of 40 points along a line, spaced approximately $3.6 \mathrm{~nm}$ apart. The dwell time for EDS acquisition at each point was $10 \mathrm{sec}$.

As-deposited films produced with no $\mathrm{Ga}_{2} \mathrm{~S}_{3}$ are columnar in cross-section, but appear equiaxed in the plane of the film. Typical grain diameters are $10-75 \mathrm{~nm}$ (Fig. 1). Upon annealing at $810^{\circ} \mathrm{C}$ for $120 \mathrm{~s}$, the grains have coarsened to be $55-90 \mathrm{~nm}$ in diameter (Fig. 2). As-deposited films produced with $\mathrm{Ga}_{2} \mathrm{~S}_{3}$ incorporated in the sputter target (Fig. 3a) have a morphology in the plane of the film similar to that of Fig. 1. Diffraction patterns (Fig. 3b) from this film indicate that equilibrium cubic SrS phase is the only crystalline phase present. Energy dispersive X-ray spectrometry (EDS) across regions approximately $2.5 \mu \mathrm{m}$ in diameter indicated the film contained approximately 1 at. \% Ce and 2 at. \% Ga.

Annealing the $\mathrm{Ga}_{2} \mathrm{~S}_{3}$-containing film at $810^{\circ} \mathrm{C}$ for $120 \mathrm{~s}$ resulted in significant grain growth; the matrix consists of typically $250-600 \mathrm{~nm}$-diameter grains (Fig. 4a). The diffraction pattern from grain ' $d$ ' in Fig $4 a$ is shown in Fig. $4 b$ and confirms this large grain is SrS (indexes as $b=[001]$ ). The EDS analysis indicates that the smaller intra- and intergranular precipitates, marked ' $e$ ' in Fig. 4a, are Ce-enriched relative to the SrS grains. Additionally, material within some grain boundary triple points (' $f$ ' in Fig. 4a) was found to be amorphous (Fig. 4c). An annular dark-field STEM image (Fig. 5) shows the position of the EDS line profile (from ' $a$ ' to ' $a$ ') acquired across a grain boundary triple point (Fig. 5) which contained amorphous material. The resulting profiles are shown as Fig. 6. Relative to the adjacent SrS grain, the amorphous phase is significantly enriched in $\mathrm{Ga}$. Intensities from points in the region of maximum $\mathrm{Ga}(\approx 40-62 \mathrm{~nm})$ were summed, as were intensities from points within the SrS grain, far from the amorphous phase $(\approx 128-142 \mathrm{~nm})$. These indicated the amorphous phase contained 44 at. $\% \mathrm{Ga}$, and the $\mathrm{SrS}$ grain $<1$ at. $\% \mathrm{Ga}$. Additionally, a Ce-rich precipitate, not readily discerned in the image, was also revealed by the EDS line profile.

The addition of $\mathrm{Ga}_{2} \mathrm{~S}_{3}$ increases the brightness of $\mathrm{SrS}: \mathrm{Ce}$ films by enhancing grain growth during annealing. Also being investigated is the possibility that $\mathrm{Ga}_{2} \mathrm{~S}_{3}$, either as a sub-sulfide or as a source of $\mathrm{Ga}$, is involved in a liquid-phase sintering mechanism, which would account for the increased grain growth observed after annealing. ${ }^{1}$

1. All films were provided by Planar America. Partial funding for this research was provided by ARPA Grant B-10-F56-S2. Research at the SHaRE User Facility sponsored by the Division of Materials Sciences, U.S. Department of Energy, under contract DE-AC05-96OR22464 with Lockheed Martin Energy Research Corp., and through the SHaRE Program under contract DE-AC05-76OR00033 with Oak Ridge Associated Universities.

DISTRIBUTION OF THIS DOCUMENT IS UNLIMITED

"The submitted manuscript has been authored by a contractor of the U.S. Government under contract No. DE-AC05-960R22464. Accordingly, the U.S.

Government retains a nonexclusive, royalty-free license to publish or reproduce the published form of this contribution, or allow others to do so, for U.S. 


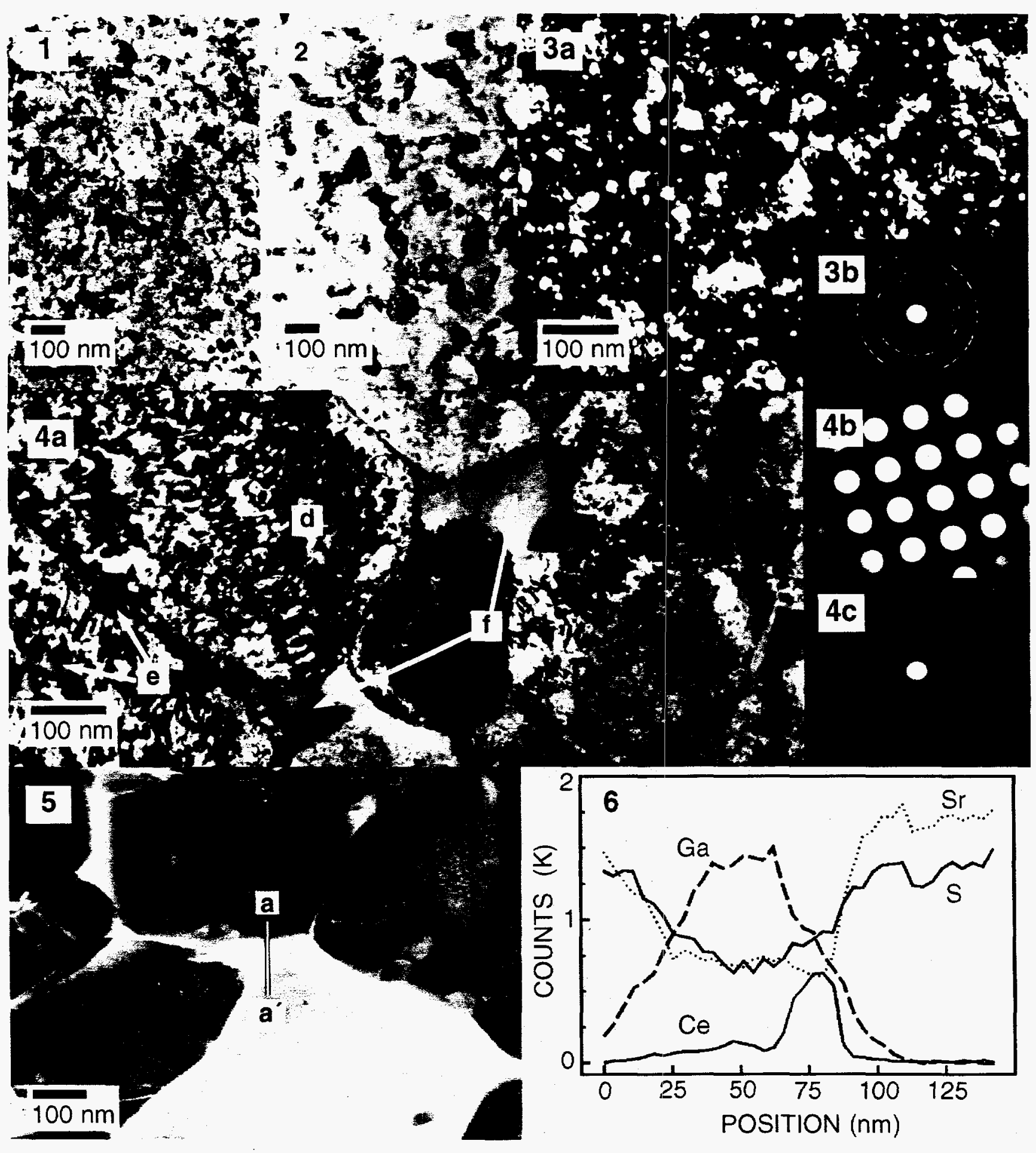

FIG. 1 - As-deposited SrS:Ce sputtered film.

FIG. 2 - SrS:Ce sputtered film, annealed at $810^{\circ} \mathrm{C}$ for $120 \mathrm{~s}$.

FIG. 3 - a) $\mathrm{Ga}_{2} \mathrm{~S}_{3}$-incorporated, as-deposited SrS:Ce film; and b) diffraction pattern.

FIG. 4 - a) $\mathrm{Ga}_{2} \mathrm{~S}_{3}$-incorporated, $\mathrm{SrS}$ :Ce film, annealed at $810^{\circ} \mathrm{C}$ for $120 \mathrm{~s}$; diffraction patterns from b) SrS and c) amorphous phase.

FIG. 5 - Amorphous grain boundary triple point used for EDS line scan (from a to a').

FIG. 6 - EDS profiles across aa' 


\section{DISCLAIMER}

This report was prepared as an account of work sponsored by an agency of the United States Government. Neither the United States Government nor any agency thereof, nor any of their employees, makes any warranty, express or implied, or assumes any legal liability or responsibility for the accuracy, completeness, or usefulness of any information, apparatus, product, or process disclosed, or represents that its use would not infringe privately owned rights. Reference herein to any specific commercial product, process, or service by trade name, trademark, manufacturer, or otherwise does not necessarily constitute or imply its endorsement, recommendation, or favoring by the United States Government or any agency thereof. The views and opinions of authors expressed herein do not necessarily state or reflect those of the United States Government or any agency thereof. 


\section{DISCLAMMER}

Portions of this document may be illegible in electronic image products. Images are produced from the best available original document. 